\title{
ANALISIS KRITIS LITURGI PERJAMUAN KUDUS HURIA KRISTEN BATAK PROTESTAN
}

\author{
Binsar Jonathan Pakpahan
}

\begin{abstract}
The liturgy of the Eucharist is a communal rite that becomes a very important foundation of the theological construction of the church. The church must have a good foundation of the Eucharist as a place where they can encounter God as a community. As a result, the theology that comes from this encounter will encourage the church to act out in her theology in the world. In 2014, Huria Kristen Batak Protestan (Protestant Batak Christian Church/HKBP) is trying to reformulate their church order. This research encourages HKBP to look at their theology of the Eucharist more seriously. By using a critical analysis towards the HKBP liturgy of the Eucharist, this paper shows the inconsistency between HKBP church documents view on the Eucharist. The inconsistency is caused by the different times of the writing of the documents, which were never synchronized.
\end{abstract}

Keywords: Holy Communion, Eucharist, Huria Kristen Batak Protestan (HKBP), Document of Baptism Eucharist Ministry (BEM), Agenda, Liturgy, Creed.

\footnotetext{
Abstrak

Liturgi Perjamuan Kudus adalah sebuah ritus komunal yang menjadi dasar penting dalam bangunan teologi sebuah gereja. Gereja harus memiliki fondasi teologi Perjamuan Kudus yang baik sebagai tempat mereka mengalami perjumpaan dengan Allah sebagai sebuah komunitas. Sebagai akibatnya, teologi yang lahir dari perjumpaan ini akan mendorong gereja untuk bereaksi di dunia di mana dia berada. Huria Kristen Batak Protestan (HKBP) pada saat ini sedang berusaha merumuskan ulang Tata Gereja dan
} 
Tata Laksana mereka. Penelitian ini mendorong HKBP untuk lebih serius dalam menelaah teologi Perjamuan Kudusnya. Melalui analisis kritis terhadap liturgi Perjamuan Kudus HKBP, makalah ini menunjukkan adanya ketidaksepahaman dokumen-dokumen gereja HKBP mengenai teologi perjamuan kudusnya. Ketidaksepahaman ini disebabkan oleh perbedaan waktu penyusunan dokumen-dokumen tersebut, yang belum disesuaikan satu dengan yang lain.

Kata-Kata Kunci: Perjamuan Kudus, Ekaristi, Protestant Batak Christian Church (HKBP), Dokumen Baptism Eucharist Ministry (BEM), Agenda, Liturgi, Pengakuan Iman.

\section{Pendahuluan}

Pada tahun 2014, Huria Kristen Batak Protestan (HKBP) akan mengadakan Sinode Agung Amandemen untuk merumuskan kembali Tata Dasar dan Tata Gerejanya (Aturan dohot Paraturan). HKBP memiliki tantangan yang besar dalam merevitalisasi dan menyelaraskan dokumen-dokumen teologinya sebelum merumuskan kembali ekklesiologinya. Empat dokumen teologi penting dalam HKBP adalah Tata Ibadah (Agenda), Pengakuan Iman (Konfessi) dan Disiplin Gereja (Rubut Parmahanion dohot Panindangion). Mereka dibuat dalam waktu dan konteks yang berbeda. Jika demikian, bagaimana sebenarnya sebuah gereja, dalam hal ini HKBP, dapat merumuskan ekklesiologinya dengan tepat? Apa titik berangkat yang perlu dicermati sebelum sebuah gereja merumuskan teologi dirinya sendiri dan panggilannya ke dalam dunia dengan baik?

Artikel ini akan mengajukan argument bahwa salah satu cara untuk menemukan ekklesiologi gereja yang tepat adalah dalam pemahaman teologi Perjamuan Kudusnya. Perjamuan Kudus adalah salah satu sakramen yang menjadi pondasi dari pemahaman teologi dan ekklesiologi sebuah gereja. Tanpa pemahaman dan perayaan Perjamuan Kudus yang baik, gereja bisa menjadi gamang dalam menentukan jatidirinya. Perjumpaan dengan Kristus dalam Perjamuan Kudus secara komunal, menjadi dasar pemahaman sebuah gereja akan ekklesiologi yang baik. Karena alasan tersebut, sebuah analisis kritis teologis perlu dilakukan terhadap formula Perjamuan Kudus gereja yang ingin menentukan dasar teologisnya. 
Dengan alasan tersebut, saya akan membahas pandangan teologi perjamuan kudus HKBP ditinjau dari formula liturgi Perjamuan Kudus di HKBP dalam keempat dokumen gereja yang disebut di atas. Metode yang akan digunakan adalah membaca teks formula dengan seksama, memaparkan sejarah perkembangannya, dan melihat apakah semua dokumen tersebut sudah saling melengkapi dan memenuhi syarat formula teologis Perjamuan Kudus yang baik.

\section{Liturgi dan Ibadah}

Liturgi (leitourgia, dari kata leïtos, "menyangkut publik/orang banyak," dan ergon, "kerja") tadinya memiliki penggunaan sekuler yaitu "pelayanan untuk orang banyak." Liturgi juga memiliki faktor ritual di dalamnya. Pada permulaan kekristenan, istilah ini dipahami dalam komunitas Yahudi sebagai "sebuah pelayanan kepada Allah atas kebaikannya terhadap umatNya." Perjanjian Baru menunjukkan penggunaan dengan arti ini dengan memberi penekanan pada pentingnya makna pengorbanan dalam kematian Kristus. Dalam era pasca para rasul, istilah leitourgia digunakan untuk ibadah, dengan para pelayan tahbisan sebagai leitourgos (orang yang memimpin leitougia). Sementara dunia Barat medieval melihat liturgi sebagai seluruh sistem ibadah, Protestan mula-mula memahami "liturgi" sebagai ibadah publik dalam berbagai bentuk. Dengan demikian, istilah "liturgi" dan "ibadah" digunakan dengan pemahaman yang hampir serupa. ${ }^{1}$

Namun demikian, pemahaman ini sebenarnya kurang tepat. Sebelum kekristenan pasca para rasul, liturgi dipahami sebagai tata perayaan Perjamuan Kudus. Istilah liturgi, yang diadaptasi dari penggunaan publik, digunakan sebagai pelaksanaan perintah yang Yesus katakan dalam perjamuan terakhir. Usaha untuk melaksanakan ulang ingatan akan ucapan Kristus inilah yang disebut sebagai liturgi. ${ }^{2}$ Dengan kembali kepada makna asal ini, J.D. Chrichton, seorang ahli liturgi, menyimpulkan bahwa liturgi adalah:

Perayaan komunal Gereja, yang adalah tubuh Kristus dan di dalamnya Kristus dan Roh Kudus adalah aktif, akan misteri

${ }^{1}$ Paul V. Marshall, "Liturgy" dalam Erwin Fahlbusch (eds.) (et al.) The Encyclopedia of Christianity Vol. 3, (Grand Rapids, William B. Eerdmands, 2003), 324.

${ }^{2}$ Lihat J. G. Davies, "Liturgy" dalam Paul Bradshaw (ed.) The New Westminster Dictionary of Liturgy and Worship. (Pennsylvania: The Westminster Press, 1986), 314-339. Di sini kita bisa melihat gambaran ringkas mengenai perbedaan tiap denominasi gereja dalam perayaan Ekaristinya. 
Paskah (ed.: penderitaan/passion, kematian, kebangkitan, dan kemuliaan Yesus Kristus). Melalui perayaan ini, yang pada dasarnya bersifat sakramental, Kristus, imam tinggi dari komunitas membuat kenyataan dari karya penyelamatan Kristus menjadi hadir dan tersedia bagi umat-Nya pada saat ini. $^{3}$

Saya akan menggunakan pengertian ini sebagai dasar penjelasan lebih lanjut.

Sementara itu, ibadah memiliki arti yang lebih luas dibandingkan liturgi. Ibadah Kristen adalah respons atas inisiatif Allah. ${ }^{4}$ Allah dilihat sebagai inisiator dari seluruh proses tersebut, dan kita memuja Allah sebagai reaksi dari inisiatif tersebut. Geoffrey Wainwright, seorang teolog sistematika dan liturgi Protestan, mengatakan bahwa dalam ibadah, "Allah dimuliakan sebagai Allah, karakternya dipuja, mengucap syukur atas karyaNya, dan kehendak-Nya kita cari." ${ }^{5}$ Dalam liturgi, kita adalah subjek pasif dari inisiatif Allah.

Ibadah selalu bersifat komunitas karena dia adalah tindakan yang dilakukan bersama. Ibadah orang Kristen mulamula adalah perkumpulan dari orang-orang percaya yang diikat dalam kasih dan iman. Gambaran Paulus akan gereja sebagai anggota dari tubuh Kristus menunjukkan betapa dekatnya komunitas mula-mula tersebut (1Kor. 12:12 dst.). Kedekatan hubungan para anggota tubuh Kristus ini kemudian digambarkan melalui perjamuan roti dan anggur.

Dengan demikian, ibadah dan liturgi dalam kekristenan pada dasarnya memusatkan perhatian kepada perayaan akan ingatan karya penyelamatan Allah dalam Yesus Kristus (Paskah adalah perayaan akan ingatan karya penyelamatan Allah untuk umat Israel dari tanah Mesir). ${ }^{6}$ Ingatan ini dirayakan sedemikian rupa, sehingga dia bukan hanya dikenang sebagai sesuatu yang terjadi di masa lampau, melainkan juga menuntut aksi dari komunitas di masa kini.

${ }^{3}$ J. D. Chrichton, "A Theology of Worship" dalam Cheslyn Jones (et.al.) (eds.), The Study of Liturgy (New York: Oxford University Press, Revised Edition: 1992), 28.

${ }^{4}$ Chrichton, “A Theology of Worship," 9.

${ }^{5}$ Geoffrey Wainwright, "Theology of Worship" dalam Paul Bradshaw (ed.) The New Westminster Dictionary of Liturgy and Worship (Pennsylvania: The Westminster Press, 1986), 505.

${ }^{6}$ Martin Stringer dalam Rethinking the Origins of the Eucharist (London: SCM Press, 2011) juga menggambarkan relasi erat antara perayaan Ekaristi jemaat Korintus dengan perayaan paskah Yahudi . 


\section{Perjamuan Kudus Sebagai Pusat Teologi Gereja}

Seorang teolog yang membawa kembali pentingnya arti liturgi Ekaristi ${ }^{7}$ dalam teologi adalah Alexander Schmemann. ${ }^{8}$ Menurutnya, teologi harus berpusat pada perayaan perjumpaan umat dengan Kristus dalam perayaan Ekaristi. Pertemuan ini menjadi penting karena dia adalah sakramen yang bersifat komunal. Dalam perayaan komunal ini, umat akan merespons ingatan mereka akan Kristus - baca: teologinya. ${ }^{9}$ Pengalaman liturgis (lex orandi) gereja membantu dia membangun teologi yang baik dan menemukan panggilan mereka untuk bersaksi di dalam dunia. ${ }^{10}$ Tidak berhenti sampai di situ, pemahaman teologi Ekaristi yang baik juga akan memperkuat pemahaman relasional sebuah gereja dengan yang lainnya. ${ }^{11}$

Dalam perayaan Perjamuan Kudus, semua anggota tubuh Kristus dipanggil untuk merayakan perjamuan bersama yang menyatukan umat. ${ }^{12}$ Perjamuan Kudus adalah tindakan bersama umat yang merupakan kelanjutan dari baptisan sebagai pintu masuk ke dalam gereja, yang adalah tindakan personal. Dengan demikian, Perjamuan Kudus akan membawa gereja menuju pembentukan dasar ekklesiologi dan eskatologi yang baik.

7 Istilah Ekaristi dan Perjamuan Kudus akan digunakan secara bergantian dengan pemahaman yang sama, yaitu peristiwa perayaan ingatan perjamuan terakhir yang dirayakan Yesus bersama murid-murid-Nya sebelum peristiwa penyaliban. Saya akan menggunakan istilah Perjamuan Kudus ketika dia secara spesifik berhubungan dengan HKBP, dan menggunakan istilah Ekaristi ketika berhubungan dengan konsep teologis secara umum.

8 John D. Zizioulas telah memperkuat argumen ini dalam The Eucharistic Communion and the World (New York: T\&T Clark International, 2011), 99-122. Dalam penelitiannya, dia mengungkapkan bahwa dalam pertumbuhan jemaat mula-mula, Paulus melhat ekklesia sebagai sebuah hal yang terikat dengan perjamuan meja Tuhan. Akibatnya, sebuah bangunan ekklesia tidak bisa lepas dari pemahaman mereka mengenai perjamuan bersama.

9 Alexander Schmemann, Introduction to Liturgical Theology trans. Asheleigh E. Moorhouse (Portland, Maine: The Faith Press Ltd., 1966), 14. Lihat juga argumennya dalam membela liturgical theology dalam Alexander Schmemann, "Liturgical Theology, Theology of Liturgy, and Liturgical Reform," St Vladimir's Theological Quarterly 13 no 4 (1969), 223.

10 Alexander Schmemann, "Liturgy and Theology," The Greek Orthodox Theological Review No. 17 (1972), 87.

${ }^{11}$ Lihat argument George Hunsinger, The Eucharist and Ecumenism (Cambridge: Cambridge University Press, 2008). Dalam penelitiannya ini Hunsinger menggambarkan tantangan keesaan gereja dan juga perpecahan yang muncul akibat perbedaan paham teologi Ekaristi gereja-gereja.

${ }^{12}$ Lihat John D. Zizioulas, Communion and Otherness (New York: T\&T Clark, 2006), 13-98. Dalam bagian ini Ziziolas menguraikan bahwa perayaan Ekaristi selalu berhubungan dengan yang lain, atau "the other." Yang lain harus dilihat sebagai rupa Allah, Kristus, bahkan diri kita sendiri. Hal ini tentu membawa tuntutan dalam hubungan kita dengan yang lain. 
Peringatan akan Kristus yang dilakukan dalam liturgi didasarkan pada institusi eis tēn emēen anamnēsin yang Max Thurian artikan sebagai "with a view to my memorial, in memorial of me, as the memorial of me." ${ }^{13}$ Peringatan yang dilakukan dalam Ekaristi memiliki arti yang berbeda bagi tiap tradisi. Lee Palmer Wandel, seorang ahli sejarah awal kekristenan modern, menyatakan bahwa gereja Lutheran dan Katolik memiliki konsep yang lebih aktif mengenai ingatan tentang Kristus di masa lalu dibandingkan tradisi Reformed. Bagi gereja Lutheran, pengenangan Kristus dalam Ekaristi adalah sebuah kesempatan untuk berefleksi akan kematian Kristus yang menyelamatkan sambil merayakan kehadiran Kristus secara nyata dalam perayaan tersebut. ${ }^{14}$

Ingatan akan Kristus ini bukan hanya mengenai masa lalu, melainkan mengubah masa kini kita untuk melangkah ke masa depan. Karena makna inilah, perayaan Ekaristi mendorong gereja merumuskan pemahaman teologis mereka mengenai perjumpaannya dengan Kristus ini. Harapan akan masa depan diimplementasikan dalam semangat persatuan, sebuah elemen yang sangat penting dalam Ekaristi. ${ }^{15}$ Dengan demikian, transformasi sosial gereja menjadi hal yang tak terelakkan dalam perayaan ini. ${ }^{16}$

Berdasarkan pemaparan mengenai makna teologis Perjamuan Kudus, kita sekarang akan melihat apa dan bagaimana HKBP memahami teologi Perjamuan Kudusnya dari berbagai dokumen gereja. Selanjutnya, kita akan menganalisis teologi Perjamuan Kudus ini sambil menyesuaikannya dengan Liturgi Perjamuan Kudus sebagai pusat teologi dan ekklesiologi HKBP.

\section{Lima Aspek Perjamuan Kudus Menurut Dokumen Baptism, Eucharist, Ministry}

Salah satu pemahaman teologis di dunia ekumenis mengenai Perjamuan Kudus ada dalam dokumen Baptism, Eucharist and Ministry yang dikeluarkan oleh Dewan Gereja Dunia. Dokumen teologi BEM yang diterima di Lima, Peru, mendefinisikan Perjamuan Kudus sebagai berikut:

13 Max Thurian, The Eucharistic Memorial II: The New Testament (London: Lutterworth Press, 1963), 35.

${ }^{14}$ Lee Palmer Wandel, The Eucharist in the Reformation: Incarnation and Liturgy (Cambridge, New York: Cambridge University Press, 2006), 260-261.

${ }^{15}$ Dong-sun Kim, The Bread for Today and the Bread for Tomorrow: The Ethical Significance of the Lord's Supper in the Korean Context (New York: Peter Lang Publishing Inc, 2001), 68-69.

${ }^{16}$ William R. Crockett, Eucharist: Symbol of Transformation (New York: Pueblo Publishing Company, 1989), 250. 
Perjamuan Kudus pada dasarnya adalah sakramen karunia yang Allah berikan kepada kita dalam Kristus melalui kuasa Roh Kudus. Setiap orang Kristen menerima karunia keselamatan ini dalam persekutuan tubuh dan darah Kristus. Dalam perjamuan Ekaristis, dalam makan dan minum roti dan anggur, Kristus mengijinkan persekutuan dengan diriNya sendiri. Allah sendiri bertindak, memberi kehidupan kepada tubuh Kristus dan membarui setiap anggotanya. Sesuai dengan janji Kristus, setiap anggota baptisan dari tubuh Kristus menerima pengampunan dosa (Mat. 26:28) dan janji akan kehidupan abadi (Yoh. 6:51-58) dalam Perjamuan Kudus. Meskipun Perjamuan Kudus adalah pada dasarnya sebuah tindak yang penuh, kita akan mempertimbangkan dalam aspek-aspek berikut ini: ucapan syukur kepada sang Bapa, peringatan akan Kristus, pemanggilan Roh Kudus, persekutuan orang percaya, dan perjamuan Kerajaan Allah." ${ }^{17}$

Dokumen Lima ini memahami karunia Perjamuan Kudus dalam cara trinitatis: bahwa ini adalah sebuah karunia Allah, dalam Kristus, dan melalui Roh Kudus. Ini adalah sebuah peristiwa di mana orang Kristen menerima karunia keselamatan melalui persekutuan dalam tubuh dan darah Kristus. Ada penekanan pada pengertian bahwa Kristus mengijinkan persekutuan dengan diriNya sendiri. Pernyataan ini mengatakan bahwa Perjamuan Kudus adalah sebuah perayaan di mana kita menerima pengampunan dosa.

Ada lima aspek utama dalam Perjamuan Kudus. Pertama, bahwa Perjamuan Kudus adalah ucapan syukur kepada Allah Bapa. Ini adalah ekspresi atas apa yang Allah Bapa berikan kepada kita. Melalui Kristus, kita mengucap syukur kepada Allah atas karya keselamatan-Nya dalam Kristus.

Kedua, Perjamuan Kudus adalah peringatan akan Kristus. Bagian ini adalah jantung dari pelaksanaan Perjamuan Kudus. Peringatan, atau anamnesis, bukan hanya sekedar mengenang apa yang telah terjadi di masa lampau, melainkan "Kristus sendiri dengan apa yang telah dia lakukan untuk kita dan seluruh ciptaan (dalam inkarnasi, pelayanan, penginjilan, pengajaran, penderitaan, kebangkitan, kenaikan, dan pengiriman Roh Kudus) hadir dalam anamnesis, mengijinkan persekutuan dengan diriNya sendiri. Perjamuan Kudus adalah untuk mencicipi parousia dan kerajaan akhirnya."

17 World Council of Churches, Baptism, Eucharist, and Ministry (Geneva: WCC, 1982), II, 2.

18 World Council of Churches, Baptism, Eucharist, and Ministry, II, 6. 
Anamnesis dalam Perjamuan Kudus juga dipercaya sebagai sumber dari segala doa Kristen; "Dalam Perjamuan Kudus, Kristus memampukan kita untuk hidup dengan-Nya, untuk menderita melalui-Nya sebagai pendosa yang ditebus, dengan sukacita dan bebas melaksanakan kehendak-Nya." ${ }^{19}$ Karya penebusan ini menuntut rekonsiliasi untuk terjadi di antara mereka yang sudah ditebus. ${ }^{20}$ Melalui Perjamuan Kudus kita diminta untuk mengingat ketidakadilan, rasisme, pemisahan dan penghapusan kemerdekaan, karena kita harus konsisten dalam usaha memulihkan situasi dunia dan kondisi manusia. Rekonsiliasi antara saudara-saudara harus dibuat sebagai bagian dari cara kita maju ke Meja Perjamuan.

Aspek ketiga dalam Perjamuan Kudus adalah pemanggilan Roh Kudus. Melalui-Nya, kita bisa mengaktualisasikan masa lalu menjadi masa kini yang hadir bagi kita sekarang. Gereja akan dikuduskan dan dibarui dalam Roh Kudus. Aspek keempat adalah persekutuan orang kudus. Ini berarti bahwa Perjamuan Kudus menuntut rekonsiliasi dari orang-orang yang sedang berkonflik untuk mendatangi meja Perjamuan (Mat. 5:23; 1 Kor. 10:16; 1 Kor. 11:20-22; Gal. 3:28). Aspek terakhir dari Perjamuan Kudus adalah pesta perayaan makan Kerajaan Allah. Aspek perayaan makan ini meminta kita juga untuk bersolidaritas dengan yang terpinggirkan.

Elemen-elemen yang masuk dalam konsep liturgi Perjamuan Kudus versi dokumen BEM adalah terbagi dalam: pembukaan, pengakuan dosa dan pengampunan dosa, pemberitaan firman, doa syafaat, pelayanan Perjamuan Kudus, dan pengutusan dan berkat.

Pelayanan Perjamuan Kudus dihubungkan dengan berbagai unsur. Yang pertama, Perjamuan Kudus harus dihubungkan dengan pelayanan Firman. Khotbah dapat berfungsi sebagai tempat menguatkan dan menyembuhkan. ${ }^{21}$ Wainwright menjelaskan bahwa khotbah dalam ibadah memiliki empat karakteristik: doksologis, anamnesis, epikletis, dan eskatologis. ${ }^{22}$ Keempat karakter ini sebaiknya selalu diingat ketika menyampaikan khotbah sebelum melaksanakan Perjamuan Kudus. Doa syafaat juga menjadi bagian penting di mana umat diminta untuk mengingat apa yang terjadi dalam konteksnya dan membawanya dalam doa kepada Allah. Ini adalah sebuah pernyataan situasional yang juga mengingat keadaan dunia ini, lalu membawanya kepada Allah.

\footnotetext{
${ }^{19}$ World Council of Churches, Baptism, Eucharist, and Ministry, II, 9.

20 World Council of Churches, Baptism, Eucharist, and Ministry, 20.

${ }^{21}$ Flora A. Keshkegian, Redeeming Memories: A Theology of Healing and Transformation (Nashville: Abingdon Press, 2000).

22 Geoffrey Wainwright, Eucharist and Eschatology (New York: Oxford University Press, 1981).
} 


\section{Sejarah dan Latar Belakang Tata Ibadah HKBP}

Agenda HKBP adalah adaptasi dari Agenda Jerman yang bernama Agende atau Kirchenagende (artinya "hal-hal yang perlu dilakukan/agenda"). Agenda HKBP aslinya ditulis dalam bahasa Batak dan kemudian diterjemahkan menjadi bahasa Indonesia.

Liturgi HKBP berasal dari Kerajaan Prussia, Jerman. Pada waktu itu (abad ke-18) terdapat bermacam-macam denominasi Gereja di Jerman, tetapi secara umum hanya ada dua aliran Gereja yang ada, yakni Lutheran dan Calvinis. Keyakinan Kaisar Frederick William III (1770 - 1840) yang memerintah Jerman waktu itu adalah apabila agama bersatu (dan hanya satu), maka negara akan menjadi kuat; dan apabila negara kuat, berarti kekuasaan Kaisar juga kuat. Karena itu negara berkepentingan untuk menyatukan berbagai denominasi yang ada di Jerman pada waktu itu, dan salah satu caranya adalah menyatukan tata ibadah yang ada agar menjadi sama di seluruh Jerman. Proses penyatuan ini juga memakan waktu bertahun-tahun dan akhirnya diputuskan untuk menggunakan tata ibadah yang adalah gabungan dari tradisi Lutheran dan Calvinis. Kaisar Frederick William III menerbitkan agenda pada tahun 1822 untuk berbagai gereja di dalam daerah kekuasaan kerajaan Prussia. Setelah mengalami revisi menyeluruh pada tahun 1879, maka sinode gereja di kerajaan Prussia menerbitkan sebuah buku tata ibadah pada tahun $1895 .{ }^{23}$ Buku tata ibadah gereja-gereja di Prussia ini bernama Agende für die Evangelische Landeskirche Preussens.

Namun sebelum publikasi tahun 1895 ini, beberapa gereja sudah terlebih dulu mengadaptasi Agenda 1822, seperti contoh dari Tata Ibadah yang diterbitkan oleh United Synod of the Evangelical Lutheran Church in the South, Amerika Serikat. ${ }^{24}$ Tata ibadah HKBP sendiri telah beberapa kali mengalami perubahan. Agenda pertama yang dipakai dicetak pada tahun 1894. Agenda yang dipakai pendeta non-Batak berbeda dengan yang dipakai oleh Guru Huria. Tata ibadah yang dipakai oleh Guru Huria tidak memiliki Votum karena dianggap kurang pantas untuk mengucapkan kata-kata tersebut. Tahun 1907, Agenda

23 "Lutheran" dalam Paul F. Bradshaw (ed.), The New SCM Dictionary of Liturgy and Worship (London: SCM Press, 2002), 79-80.

24 Seperti ditulis dalam Hans-Christoph Schmidt-Lauber, "The Lutheran Traditions in the German Lands" dalam Geoffrey Wainwright and Karen B. Westerfield Tucker (eds.) The Oxford History of Christian Worship (New York: Oxford University Press, 2006), 411-412. Bandingkan dengan buku tata ibadah tahun 1888 dalam The Book of Worship terbitan United Synod of the Evangelical Lutheran Church in the South (Charleston, SC: Committee of United Synod on Common Book Worship, 1907). 
dicetak ulang tetapi tidak memiliki perubahan yang signifikan. Pada tahun 1918 Agenda disamakan, dan cetakan tahun 1937-lah yang HKBP pakai pada saat ini. ${ }^{25}$

\begin{tabular}{|c|c|}
\hline Tata Ibadah Prussian 1895 & $\begin{array}{l}\text { Tata Ibadah United } \\
\text { Synod of the Evangelical } \\
\text { Lutheran Church in the } \\
\text { South } 1888\end{array}$ \\
\hline $\begin{array}{l}\text { Lagu Pembukaan } \\
\text { P: "Di dalam nama } \\
\text { Allah Bapa, Anak, dan Roh } \\
\text { Kudus." } \\
\text { atau "Pertolongan kita } \\
\text { adalah dalam nama..." }\end{array}$ & $\begin{array}{l}\text { Hymne untuk } \\
\text { mengundang kehadiran } \\
\text { Roh Kudus } \\
\text { P: "Di dalam nama } \\
\text { Allah Bapa, Anak, dan Roh } \\
\text { Kudus." }\end{array}$ \\
\hline Teks pembukaan dari & Pengakuan Dosa \\
\hline Bapa..." & $\begin{array}{l}\text { Introitus }^{26} \\
\text { Gloria Patri }\end{array}$ \\
\hline $\begin{array}{l}\text { Pengakuan dosa, Kyrie, } \\
\text { dan berita anugerah } \\
\text { "Kemuliaan bagi Allah } \\
\text { di tempat yang } \\
\text { mahatinggi..."(dalam } \\
\text { perayaan2 khusus) } \\
\text { "Damai sejahtera Allah }\end{array}$ & $\begin{array}{l}\text { Kemuliaan bagi Allah Bapa, } \\
\text { dan bagi Anak-Nya, dan } \\
\text { bagi Roh Kudus, seperti } \\
\text { pada mulanya, sekarang, dan } \\
\text { sampai selama-lamanya, } \\
\text { dalam dunia tanpa akhir. }\end{array}$ \\
\hline besertamu..." & Kyrie \\
\hline $\begin{array}{l}\text { Collect/Doa situasi - Doa } \\
\text { pembukaan }\end{array}$ & $\begin{array}{l}\text { Tuhan kasihani kami, } \\
\text { Kristus kasihani kami, } \\
\text { Tuhan kasihani kami. }\end{array}$ \\
\hline $\begin{array}{l}\text { Pembacaan Surat Rasul } \\
\text { (Epistel) }\end{array}$ & $\begin{array}{l}\text { Gloria In Excelsis } \\
\text { P : Kemulliaan bagi Allah di } \\
\text { tempat yang maha tinggi. }\end{array}$ \\
\hline $\begin{array}{l}\text { Menyanyi pujian (with } \\
\text { "Praise be to you, O } \\
\text { Christ" and "Glory be to } \\
\text { You, o Lord") }\end{array}$ & $\begin{array}{l}\text { Collect/Doa situasi - doa } \\
\text { pembukaan } \\
\text { Pembacaan Surat } \\
\text { Rasul/Epistle for the Day } \\
\text { Halleluya }\end{array}$ \\
\hline
\end{tabular}

25 Bandingkan J.R. Hutauruk, Labir, Berakar dan Bertumbuh di dalam Kristus (Tarutung: HKBP, 2011), 181-183 yang juga memberikan informasi yang kurang lebih serupa.

${ }^{26}$ Introitus atau introit adalah bagian dari mazmur atau himne yang berkenaan dengan tema dari hari itu atau Minggu tersebut. 


\begin{tabular}{|c|c|}
\hline $\begin{array}{l}\text { Pengakuan Iman Rasuli } \\
\text { (atau himne Luther "Wir } \\
\text { glauben alle an einen } \\
\text { Gott") }\end{array}$ & $\begin{array}{l}\text { Halleluya dan kalimat } \\
\text { penguatan } \\
\text { Pembacaan Injil hari ini }\end{array}$ \\
\hline $\begin{array}{l}\text { Menyanyi himne sebelum } \\
\text { khotbah }\end{array}$ & Pengakuan Iman Rasuli \\
\hline Salam dari pengkhotbah & Persembahan \\
\hline Khotbah & \\
\hline $\begin{array}{l}\text { Menyanyi himne } \\
\text { (persembahan) }\end{array}$ & $\begin{array}{l}\text { Di sini pelengkeap, doa syafaat } \\
\text { dipanjatkan. }\end{array}$ \\
\hline $\begin{array}{l}\text { Pembacaan warta jemaat } \\
\text { dan permintaan doa } \\
\text { khusus }\end{array}$ & $\begin{array}{l}\text { Doa Bapa Kami, Berkat } \\
\text { Harun }\end{array}$ \\
\hline $\begin{array}{l}\text { Berkat/doa dari mimbar atas } \\
\text { firman }\end{array}$ & \\
\hline Menyanyi himne & \\
\hline Doa syafaat & \\
\hline $\begin{array}{l}\text { Doa Bapa kami, Berkat } \\
\text { Harun }\end{array}$ & \\
\hline
\end{tabular}

(Tabel Tata Ibadah Minggu Umum Prusia 1895, dan United Synod of Evangelical Lutheran in the South 1888)

Tata ibadah Perjamuan Kudus dalam liturgi Prussia adalah sebagai berikut:

Jika Perjamuan Kudus:

Ayat pembimbing atau himne untuk Perjamuan Kudus

"Allah besertamu..." (Umat: "dan besertamu juga.")

Persiapan Perjamuan Kudus (kecuali jika pengakuan dan pengampunan dosa yang disiapkan sudah dilakukan sebelum ibadah)

Doa Ekaristi: dialog, pembukaan, Sanctus, doa untuk komunitas yang berbuah

Doa Bapa Kami (di sini atau sesudah pengucapan institusi Perjamuan Kudus) 
"Berlutut dan dengarlah" Institusi Penetapan Perjamuan

Kudus

Agnus Dei

Salam Damai

Doa untuk pengampunan dosa dan kepatuhan orang beriman Undangan (Matius 11:28 atau Mazmur 34:8a)

Perjamuan Kudus ("Ambillah dan makanlah," berdasarkan kalimat institusi)

Doa ucapan syukur setelah Perjamuan Kudus

Berkat Harun, Amin, dan ayat himne penutup

Tata Ibadah Prussia 1895 dan Tata Ibadah United Synod of Evangelical Lutheran in the South 1888 bisa kita lihat datang dari akar yang sama. Ada banyak kemiripan dalam tata ibadah ini, terutama dalam posisi utama khotbah yang menjadi puncak dari ibadah. Semua unsur liturgis yang lain diletakkan sebelum khotbah kecuali persembahan dan doa syafaat. Ketika Perjamuan Kudus dirayakan, dia menjadi puncak dari ibadah itu

Liturgi Prussia memiliki ibadah persiapan perjamuan kudus sebelum ibadah utama. Hal ini didasari oleh perintah untuk memeriksa diri sendiri yang ditulis oleh Paulus dalam 1Korintus 11:28. Meskipun demikian, ibadah persiapan Perjamuan Kudus adalah sebuah pilihan dan bukan kewajiban. HKBP sendiri memiliki ibadah persiapan yang sudah jarang digunakan. ${ }^{27}$

Tata Ibadah Minggu biasa Agenda HKBP tahun 1904 tidak memiliki banyak perbedaan dengan Agenda HKBP 2013 (versi perubahan besar terakhir ada di tahun 1937). Perbedaan yang bisa disebutkan di sini adalah waktu pembacaan "warta jemaat" yang dilakukan setelah khotbah di Agenda 1904, sementara Agenda 2013 meletakkannya sebelum khotbah. Perubahan lain adalah waktu pemberian persembahan yang ada sesudah khotbah di Agenda 1904, menjadi dua kali waktu pelaksanaannya di Agenda 2013, yaitu sebelum dan sesudah khotbah. $^{28}$

27 Karena keterbatasan waktu dan tempat, saya tidak akan menjelaskan sejarah lengkap perkembangan Tata Ibadah Prussia menjadi Tata Ibadah HKBP. Kita akan melihat bentuk ibadah HKBP sekarang berdasarkan Agenda 1904, Agenda versi setelah 1937 (dengan revisi kecil), lalu melihat formula Perjamuan Kudus di dalamnya.

28 Perubahan letak persembahan ini sebenarnya harus juga dibicarakan oleh Komisi Liturgi dan Komisi Teologi. Dalam sebuah Pembinaan Calon Pendeta 2004, Kepala Biro Personalia waktu itu menjelaskan bahwa perpindahan tempat kolekte adalah demi alasan praktis menghindari pengedaran tiga kantung persembahan dalam satu waktu. Persembahan harus selalu dilakukan sesudah khotbah sebagai tanda kepercayaan dan iman atas berkat Tuhan yang kita terima dan bukan sebelumnya. Karena itu, sampai sekarang lagu yang dinyanyikan sebelum khotbah adalah tentang persiapan diri akan Firman Tuhan yang akan didengarkan, dan bukan lagu persembahan. Usul 


\section{Liturgi Perjamuan Kudus di HKBP}

Pengakuan Iman HKBP 1996 menyatakan bahwa HKBP merayakan Perjamuan Kudus sebagai tanda dari Gereja yang benar (Konfessi HKBP Pasal 7E bagian b). Pasal 8 Pengakuan Iman HKBP menyatakan,

B) Perjamuan Kudus

Perjamuan kudus adalah memakan roti sebagai saluran tubuh Tuhan Yesus Kristus dan meminum anggur sebagai saluran darah Yesus Kristus agar kita menerima keampunan dosa, kehidupan dan kebahagiaan. Perjamuan Kudus adalah pesta sukacita bagi orang yang ikut, karena itu adalah pendahuluan dari persekutuan yang kekal. Dan itu juga adalah tanda syukur mengingat penebusan Tuhan Yesus Kristus, dan jalan menerima kasih karuniaNya (Mat. 26:20-30; Mrk. 14:17-26; Luk. 22:14-20; 1Kor. 11:17-34).

Dengan ini kita menganjurkan supaya kita lebih sering ikutserta dalam Perjamuan Kudus.

Kita menolak kebiasaan beberapa Gereja yang hanya memberikan roti kepada warga Gereja, tanpa anggur. Demikian juga pendapat yang mengatakan ada lebih dari dua sakramen.

Tekanan makna Perjamuan Kudus yang diberikan di sini adalah bahwa Perjamuan Kudus adalah saluran tubuh dan darah Tuhan Yesus agar menerima keampunan dosa, kehidupan dan kebahagiaan. HKBP menganggap pertemuan dengan Kristus dalam Perjamuan Kudus sebagai sebuah pesta sukacita dan peringatan aktif yang menjadi jalan untuk mengucap syukur, mengingat tindak penyelamatan Kristus, dan jalan menerima karunia Kristus.

Pemaknaan Perjamuan Kudus ini adalah penyempurnaan dari pemahaman Perjamuan Kudus dalam HKBP 1951 Pasal 10 B yang menyatakan,

Kita percaya dan menyaksikan :

Perjamuan Kudus ialah: Memakan roti, dengan roti mana (parbitean) kita terima daging dari Yesus Kristus Tuhan kita

saya, kita harus mengembalikan letak persembahan yang secara teologis benar, yaitu sesudah khotbah. 
dan meminum anggur, dengan anggur mana kita terima darah Tuhan kita Yesus Kristus, supaya kita peroleh keampunan dosa, hidup dan sejahtera. (1Kor. 11: 17 - 34; Mat. 26; Mrk. 14; Luk. 22).

Dengan ajaran ini kita menolak dan melawan ajaran yang mengatakan: Hanya rotilah yang dapat diberikan kepada anggota jemaat, tetapi anggur tidak. Sebab dengan demikianlah Firman Tuhan Yesus waktu Ia memesankan Perjamuan Kudus itu: "Minumlah kamu sekalian dari cawan itu." Dan ini pulalah yang diikuti oleh Gereja pada waktu pertama (1Kor. 11: $24-25)$.

Juga tidak ada alasan dari Firman Tuhan untuk mengartikan wujud dari missa, di mana dikatakan, bahwa Tuhan kita dikorbankan lagi setiap kali dilakukan missa, karena itu kita menolak ajaran ini.

Salah satu catatan penting dari perbandingan ini adalah bagian mengenai sakramen Perjamuan Kudus sebagai bagian sukacita yang membawa kebahagiaan dan kasih karunia. Kata "pesta sukacita" juga dimasukkan untuk memberi rasa baru sukacita di luar kecaman dosa. Karena itu, Pengakuan Iman 1996 juga menambahkan bagian, "Dengan ini kita menganjurkan supaya kita lebih sering ikut-serta dalam Perjamuan Kudus." Perjamuan Kudus adalah sebuah pesta perayaan bersama dengan saudara-saudara dalam Kristus, berbeda dengan formula yang diajukan dalam Pengakuan Iman 1951.

Bagian kedua yang baru adalah "Dan itu juga adalah tanda syukur mengingat penebusan Tuhan Yesus Kristus, dan jalan menerima kasih karuniaNya.'Kalimat ini menunjukkan aspek kedua dari Perjamuan Kudus sebagai peringatan akan karya Kristus. Pengakuan Iman 1951 tidak menunjukkan aspek peringatan/anamnesis secara spesifik. Karena itu, kita bisa menyimpulkan bahwa Pengakuan Iman 1996 memasukkan pengertian teologis yang baru mengenai Perjamuan Kudus.

Pengertian baru ini muncul dari dokumen Baptism, Eucharist and Ministry (WCC 1982) yang merupakan pemahaman teologis yang baru dalam dunia ekumenis, seperti yang telah kita lihat di bagian sebelumnya. Sementara itu, Liturgi Perjamuan Kudus HKBP sendiri masih mengikuti pendekatan teologis akan makna Perjamuan Kudus yang ada dari Liturgi Prussia tahun 1895. Semua orang didorong untuk berpartisipasi sesering mungkin dalam Perjamuan Kudus, kecuali mereka yang sedang menjalani disiplin gereja (RPP HKBP 1987, 16). Orang yang sudah tidak berada dalam disiplin gereja akan diterima kembali dalam Perjamuan Kudus. 
Berdasarkan aspek persiapan, ada dua macam liturgi Perjamuan Kudus dalam Agenda, yaitu dengan ibadah persiapan dan tanpa ibadah persiapan. Saya akan membahas tata ibadah tanpa ibadah persiapan karena lebih sering digunakan. ${ }^{29}$

Berikut Tata Ibadah Perjamuan Kudus HKBP beserta dengan pembagian elemen liturgis (dengan menggunakan tanda kurung) yang saya tambahkan sendiri.

\section{Tata Kebaktian Perjamuan Kudus bersama dengan Persiapannya}

\section{NYANYIAN BERSAMA}

2. (SALAM DAMAI) BERKAT: Damai sejahtera Allah yang melampaui segala akal, akan memelihara hati dan pikiranmu dalam Kristus Yesus. Amin.

(a. Doa Epiklesis) Marilah kita berdoa, Ya Tuhan Allah yang Mahamurah, Bapa kami yang ada di surga. Hadirlah di tengah-tengah kami. Pada waktu kami menerima PerjamuanMu yang kudus itu, berikanlah Roh Kudus kepada kami masing-masing, agar kami percaya kepada AnakMu Yesus Kristus Penebus kami. Tolonglah kami untuk menyangkal diri kami, agar kami dapat mengikuti Tuhan Yesus Kristus, dan iman kami semakin hidup dan kuat. Gerakkanlah hati kami agar selalu merindukan kedatanganMu yang keduakalinya. Amin.

Doa Epiklese yang disampaikan menunjukkan hubungan antara Allah Bapa, Yesus Kristus dan Roh Kudus dalam sebuah persekutuan. Peserta Perjamuan meminta Roh Kudus untuk datang sehingga iman dalam Kristus bisa dikuatkan. Roh Kudus juga berfungsi untuk memiliki kekuatan dalam dunia menahan penderitaan. Ada juga bagian tentang penantian akan kedatangan Kristus yang kedua kali dalam doa ini. Harapan akan kedatangan kembali dihubungkan dengan keteguhan dalam penderitaan.

(b. Undangan dan Bimbingan) Jemaat yang dikasihi Allah, kita bermaksud untuk menerima Perjamuan Kudus. Oleh karena itu kita perlu meneliti diri kita, apakah kita layak menerima Perjamuan Kudus itu supaya tidak seorang pun dari antara kita yang kena Hukuman Allah.

29 Meskipun demikian, saya tetap mendorong adanya revitalisasi Perjamuan Kudus dengan Ibadah Persiapan yang terpisah sebagai tanda kesiapan umat maju ke meja Perjamuan dengan hati yang siap berekonsiliasi dengan Allah dan sesama. 
Sebab mereka yang layak menerima Perjamuan Kudus itu hanyalah orang yang menyesali segala perbuatannya yang jahat, dan yang mengaku dosa-dosanya, dan yang yakin akan keampunan dosa yang dianugerahkan Tuhan Yesus Kristus. Dan mereka yang menerima Perjamuan Kudus itu, hendaknya jangan lagi melayani iblis, dan harus menghindari dosa. Jauhkanlah dirimu daripada hal-hal yang jahat, dari iri hati dan kebencian. Tetapi hendaklah kamu selalu merenungkan Tuhan Yesus Kristus yang telah mati dan bangkit kembali, supaya kamu layak menerima Perjamuan Kudus itu.

Pendeta akan meminta umat untuk memeriksa diri sendiri apakah mereka siap untuk menerima Perjamuan Kudus. Tujuannya agar orang tidak menerima hukuman Allah. Mereka yang menerima Perjamuan diminta untuk mengakui dosadosanya. Formula ini juga menunjukkan peringatan juga untuk orang-orang yang telah mengikutinya untuk tidak lagi melayani Iblis dan menghindari dosa. ${ }^{30}$

(c. Pengakuan Dosa dan Pemeriksaan Diri) Karena itu marilah kita meneliti diri kita masing-masing, jawablah pertanyaanpertanyaan ini (Jemaat dipersilahkan berdiri):

1. Apakah engkau mengakui, bahwa engkau adalah orang berdosa sejak engkau lahir dan karena pelanggaran-pelanggaranmu sendiri atas Hukum Allah? Jika demikian, jawablah: YA!

2. Apakah engkau menyesali dosa-dosamu dan engkau merindukan keampunannya? Jika demikian, jawablah dengan: YA!

3. Apakah engkau mengakui bahwa Tuhan Yesus telah datang ke dunia ini untuk menyelamatkan orang berdosa; Dia yang telah mati dan bangkit kembali untuk menanggung dan menghapuskan dosamu? Jika demikian, jawablah dengan: YA!

4. Apakah engkau mau menjauhkan dirimu dari kebencian dan kedengkian? Seterusnya, apakah engkau mau berdamai dengan orang yang menyakiti hatimu dan mau mengampuninya sebagaimana engkau mengharapkan Allah akan mengampuni dosamu? Jika demikian, jawablah dengan: YA!

${ }^{30}$ Berdasarkan pengamatan pribadi, beberapa anggota jemaat memilih untuk tidak mengikuti Perjamuan Kudus karena ketakutan mereka menjawab pertanyaan ini. Mereka merasa bahwa mereka tidak bisa menjauhi hal yang jahat dan mereka takut akan hukuman Allah karena ketidakmampuan tersebut. Ini adalah kesalahpahaman mengenai bagian pemeriksaan diri karena akhirnya jemaat justru menjauh dari karunia yang ditawarkan Allah. 
Sampai bagian ini, kita melihat bahwa fokus utama formula ini adalah ingatan akan kematian Kristus untuk pengampunan dosa. ${ }^{31}$ Fokus utama dari pengenangan Kristus adalah pengampunan dosa. Meskipun hal ini adalah salah satu tujuan dari pengenangan dalam Perjamuan Kudus, dia bukanlah satu-satunya tujuan perayaan Perjamuan Kudus. Formula ini masih banyak dipengaruhi teologi Eropa Barat abad pertengahan - pasca Reformasi Gereja - yang melihat bahwa Perjamuan Kudus bertujuan untuk menghapuskan dosa manusia. Umat perlu untuk mengetahui kapan dia akan menerima pengampunan dosa setelah surat penghapusan dosa dan sakramen pengakuan dosa ditiadakan dalam tradisi Protestan.

(d. Pengampunan Dosa) Sekarang, marilah kita merendahkan diri serta mengaku dosa-dosa kita. Ikutilah doa ini dalam hati!

Ya Tuhan Allah, Bapa kami dalam Tuhan Yesus Kristus! Kami adalah orang berdosa. Kami sering melanggar hukumMu. Jika Engkau membalaskan kejahatan kami, maka kami sepantasnya menerima hukumanMu. Tetapi karena kasih setiaMu dan karena Yesus Kristus AnakMu yang telah diserahkan karena dosa kami, kami berani datang memohon kepadaMu: Kasihanilah kami, terimalah kami, ampunilah dosa-dosa kami. Berikanlah kepada kami Roh yang Kudus agar kami beroleh kekuatan melawan si jahat dan melakukan perbuatan-perbuatan yang sesuai dengan kehendakMu selama hidup kami. Amin.

Saudara-saudara yang telah menyesali dosamu dan yang rindu akan pengasihan Allah, kiranya saudara menerima sesuai dengan kepercayaanmu, berdasarkan Firman Tuhan Yesus, Aku berkata kepadamu: Yakinlah, dosamu telah diampuni, dengan Nama Allah Bapa, Anak dan Roh Kudus. Amin.

(e. Doa Bapa Kami) (Hanya Pendeta): Bapa kami yang di sorga dst.

Bagian ini menunjukkan bahwa fokus dari pengakuan dosa adalah tentang keadaan umat yang penuh dosa yang pantas menerima hukuman Allah, namun menerima pengampunan dosa

31 Ada dua pertanyaan yang ditanyakan dalam Formula Persiapan Perjamuan Kudus yang tidak dicantumkan dalam Formula ini, yaitu: (5.) Maukah engkau meninggalkan kedengkian dan kebencian dan apakah engkau mau berdamai dengan orang yang berdosa kepadamu, apakah engkau mau mengampuninya seperti engkau mengharapkan Allah akan mengampuni dosamu? Dan (6) Apakah engkau akan berusaha melawan dosa, dan menuruti Firman Tuhan dengan segenap hatimu. 
atas pengakuannya tersebut. Hal yang patut disebutkan di sini adalah bahwa kalimat absolusi dosa (Yakinlah, dosamu telah diampuni) yang ditulis di sini tidak tercantum dalam tata ibadah kebaktian minggu HKBP. Kebaktian Minggu biasa HKBP menyebutkan, "Dengarlah janji Tuhan akan pengampunan dosa" yang diikuti dengan pembacaan ayat yang berhubungan dengan tema ini. Bagian pengampunan dosa tersebut diakhiri dengan ucapan "Kemuliaan bagi Allah di tempat yang mahatinggi." Pengucapan kalimat absolusi dalam Perjamuan Kudus memperkuat kesan bahwa perayaan inilah yang menyediakan sarana pengampunan dosa dalam ibadah.

\section{NYANYIAN BERSAMA}

(f. Institusi - Penetapan Perjamuan Kudus) Sekarang, dengarkanlah amanat penetapan Perjamuan Kudus itu. Pada malam tatkala Yesus diserahkan... (dari formulasi yang terdapat dalam 1 Korintus 11) ... Sekarang marilah, semuanya telah tersedia! Lihat dan nikmatilah pemberian Allah.

\section{PERJAMUAN KUDUS (Bernyanyi: Sambil Menerima Perjamuan)}

Tuhan Yesus Kristus berkata: Ambillah dan makanlah! Inilah tubuhKu yang diserahkan untuk menebus engkau. Itulah yang memelihara dan meneguhkan imanmu kepadaNya agar engkau menerima kehidupan yang kekal. Amin.

Tuhan Yesus berkata: Ambillah dan minumlah. Inilah darahKu yang ditumpahkan menjadi keampunan dosamu. Itulah yang memelihara dan meneguhkan imanmu kepadaNya, agar engkau menerima hidup yang kekal. Amin.

Pulanglah dengan sejahtera!

\section{NYANYIAN BERSAMA (Nyanyian puji-pujian)}

Proses Perjamuan dalam liturgi HKBP adalah personal dan komunal. Sekelompok orang akan maju bersama ke Meja Perjamuan untuk menerima roti dan anggur. Hanya pendeta yang akan membagikan roti dan anggur kepada umat yang datang ke depan altar. ${ }^{32}$ Hal yang positif adalah bahwa mereka akan makan

\footnotetext{
32 Secara umum, semua gereja HKBP melakukan pelayanan Perjamuan Kudus dengan cara ini, kecuali HKBP Menteng yang sudah menggunakan cara lain. Di sana, pendeta akan memberikan roti dan anggur
} 
dan minum sebagai sebuah persekutuan dan tetap merasakan sapaan Allah secara pribadi.

\section{DOA (Doa Syukur)}

"Pujilah Tuhan, hai jiwaku! Pujilah NamaNya yang kudus hai segenap batinku! Pujilah Tuhan hai jiwaku, dan janganlah lupakan segala kebaikanNya. Dia yang mengampuni segala kesalahanmu, yang menyembuhkan segala penyakitmu. Dan Dia yang menebusmu dari lubang kubur, yang memahkotai engkau dengan kasih setia dan rahmat... (Mazmur 103:8-13) ... Amin."

Kita bisa melihat lagi bagaimana penekanan terhadap pengampunan dosa ditunjukkan dalam formula doa syukur Perjamuan Kudus dari Mazmur 103. Doa ini menunjukkan bahwa Allah adalah pengasih dan tidak menyimpan dendam terhadap manusia; Allah telah menebus umat-Nya dan melindungi mereka dalam kasih dan karunia. Di akhir doa Mazmur 103, sekali lagi kita bisa melihat bahwa kasih Allah ditunjukkan kepada semua orang berdosa melalui kematian Kristus di kayu salib.

\section{BERKAT (Berkat Harun)}

\section{NYANYIAN BERSAMA}

Berdasarkan pemaparan ini, formula Perjamuan Kudus HKBP ternyata belum memiliki kelima aspek Ekaristi, seperti yang tertuang dalam dokumen iman BEM. Kita menemukan aspek pengucapan syukur kepada Bapa; sedikit penyebutan mengenai pengenangan Kristus (dengan fokus utama pada tentang pengampunan dosa); dan penyertaan Roh Kudus. Aspek persekutuan orang percaya tidak sepenuhnya terlihat dalam formula ini, apalagi aspek perjamuan makan Kerajaan Allah.

Secara umum, formula ini memberi terlalu banyak penekanan terhadap aspek pengampunan dosa dan tidak menunjukkan harapan eskatologis dalam penderitaan di dunia dengan proporsional. Formula ini tidak menunjukkan perayaan makan sukacita, yang justru sudah dicantumkan dalam Pengakuan Iman 1996. Kristus tidak hanya mati di kayu salib, Dia juga bangkit dan naik ke surga kembali kepada Bapa.

Yang mengejutkan adalah bahwa formula Perjamuan Kudus tidak memiliki bagian anamnesis. Setelah pengampunan dosa, liturgi langsung masuk ke bagian institusi, perjamuan, dan

kepada penatua yang kemudian membagikannya kepada jemaat yang duduk di tempatnya masing-masing. 
pengucapan syukur. Tidak ada bagian dalam Formula Perjamuan ini yang menyebutkan bagian pengenangan kehidupan Kristus. Ini memperlihatkan kekurangan kedalaman pemahaman teologis.

Dengan melihat Formula ini secara kritis, kita bisa menyimpulkan bahwa dia memiliki kekurangan kerangka teologis yang sesuai dengan Pengakuan Iman 1996 yang justru sudah lebih baik dalam pemahamannya. Definisi Perjamuan Kudus dalam Pengakuan Iman HKBP Tahun 1996 pasal 8 belum diterjemahkan dalam liturgi Perjamuan Kudus HKBP yang digunakan hingga saat ini (2014).

Liturgi Perjamuan Kudus HKBP saat ini lebih mirip kepada formulasi Pengakuan Iman 1951 - jika bukan Agenda 1904, daripada pengertian yang lebih baru yang tercantum di Pengakuan Iman 1996. Pembaruan paham teologis di tahun 1996 tidak diikuti dengan pembaruan formula liturgis.

\section{Penutup}

Pemaparan ini bertujuan untuk menunjukkan kurangnya pemahaman teologis yang benar mengenai Perjamuan Kudus dalam Formula Liturgi HKBP yang tidak sejalan dengan Pengakuan Iman HKBP 1996. Penekanan pada aspek pengampunan dosa sepertinya melupakan aspek Perjamuan Kudus yang lain, yaitu unsur sukacita dan perjamuan makan Kerajaan Allah. Dengan pemahaman teologi Perjamuan Kudus yang baik, maka HKBP bisa merumuskan identitasnya dalam ekklesiologi yang lebih baik lagi.

Berdasarkan survey kecil terhadap para pendeta yang melayani di gereja-gereja HKBP di DKI Jakarta, saya menemukan bahwa kebanyakan gereja hanya melaksanakan dua kali perayaan Perjamuan Kudus setiap tahun (Jumat Agung dan Natal). ${ }^{33}$ Hal ini juga didukung oleh pemahaman bahwa Perjamuan Kudus adalah perayaan spesial yang tidak harus dilakukan setiap waktu, meskipun Pengakuan Iman HKBP 1996 menyatakan hal yang sebaliknya.

Berdasarkan penelitian ini, saya menyimpulkan bahwa HKBP harus merumuskan kembali dan merevitalisasi formula Perjamuan Kudus yang baru. Perumusan formula baru ini penting untuk segera dilakukan agar HKBP bisa menemukan dasar yang kuat merumuskan ekklesiologi yang tepat dalam menghadapi

33 Pernyataan ini dikuatkan oleh Ramlan Hutahaean, mantan Sekretaris Jenderal HKBP periode 2008-2012 dalam Tradisi Teologis HKBP (Bekasi: Pustaka Efata, 2013), 76-77, yang menyatakan bahwa tujuan perayaan Perjamuan sebanyak 2-3 kali setahun adalah "supaya setiap orang yang menerima perjamuan kudus benar-benar menghayati makna dari pelayanan sakramen itu." 
konteks pelayanannya yang terus berubah. Penemuan ini membuat saya mendorong gereja-gereja lain untuk meneliti ulang formula liturgi Ekaristi mereka, menyesuaikannya dengan perangkat teologis gereja, dan merumuskan kembali formula yang mengandung lima unsur Ekaristi yang dibahas di atas.

\section{Tentang Penulis}

Binsar Jonathan Pakpahan adalah Pendeta HKBP dan Dosen tetap di ST'T Jakarta, mengajar bidang studi Filsafat, Etika, Teologi Sosial, Filsafat Ilmu dan Teologi dan Etika Terapan, serta Teologi Kontemporer. Makalah ini pernah disampaikan dalam Rapat Pendeta HKBP Distrik 28, DKI Jakarta, di Hotel Panorama, Lembang, Jawa Barat, 3 September 2013. 


\section{Bibliografi}

Chrichton, J. D. "A Theology of Worship" dalam Cheslyn Jones (et.al.) (eds.), The Study of Liturgy. New York: Oxford University Press, Revised Edition: 1992.

Crockett, William R. Eucharist: Symbol of Transformation. New York: Pueblo Publishing Company, 1989.

Davies, J. G. "Liturgy" dalam Paul Bradshaw (ed.) The New Westminster Dictionary of Liturgy and Worship. Pennsylvania: The Westminster Press, 1986: 314-339.

HKBP. Agenda HKBP. Pematangsiantar: Percetakan HKBP, 2007.

HKBP. Konfessi HKBP 1951. Tarutung: HKBP, 1951.

HKBP. Konfessi HKBP 1996. Tarutung: HKBP, 1996.

HKBP. Ruhut Parmahanion dohot Paminsangon. Tarutung: HKBP, 2000.

Hunsinger, George. The Eucharist and Ecumenism. Cambridge: Cambridge University Press, 2008.

Hutahaean, Ramlan. Tradisi Teologis HKBP. Bekasi: Pustaka Efata, 2013.

Hutauruk, J.R. Lahir, Berakar dan Bertumbuh di dalam Kristus. Tarutung: HKBP, 2011.

Keshkegian, Flora A. Redeeming Memories: A Theology of Healing and Transformation Nashville: Abingdon Press, 2000.

Kim, Dong-sun. The Bread for Today and the Bread for Tomorrow: The Ethical Significance of the Lord's Supper in the Korean Context. New York: Peter Lang Publishing Inc, 2001.

Marshall, Paul V. "Liturgy" dalam Erwin Fahlbusch (eds.) (et al.) The Encyclopedia of Christianity Vol. 3. Grand Rapids, William B. Eerdmands, 2003.

Schmemann, Alexander. "Liturgical Theology, Theology of Liturgy, and Liturgical Reform," St Vladimir's Theological Quarterly 13 No. 4, 1969.

Schmemann, Alexander. "Liturgy and Theology," The Greek Orthodox Theological Review No. 17, 1972.

Schmemann, Alexander. Introduction to Liturgical Theology trans. Asheleigh E. Moorhouse. Portland, Maine: The Faith Press Ltd., 1966. 
Schmidt-Lauber, Hans-Christoph. "The Lutheran Traditions in the German Lands" dalam Geoffrey Wainwright and Karen B. Westerfield Tucker (eds.) The Oxford History of Christian Worship. New York: Oxford University Press, 2006.

Stringer, Martin. Rethinking the Origins of the Eucharist. London: SCM Press, 2011.

Thurian, Max. The Eucharistic Memorial II: The New Testament. London: Lutterworth Press, 1963.

United Synod of the Evangelical Lutheran Church in the South. The Book of Worship. Charleston, SC: Committee of United Synod on Common Book Worship, 1907.

Wainwright, Geoffrey. "Theology of Worship" dalam Paul Bradshaw (ed.) The New Westminster Dictionary of Liturgy and Worship. Pennsylvania: The Westminster Press, 1986.

Wainwright, Geoffrey. Eucharist and Eschatology. New York: Oxford University Press, 1981.

Wandel, Lee Palmer. The Eucharist in the Reformation: Incarnation and Liturgy. Cambridge, New York: Cambridge University Press, 2006.

World Council of Churches. Baptism, Eucharist, and Ministry. Geneva: WCC, 1982.

Zizioulas John D. The Eucharistic Communion and the World. New York: T\&T Clark International, 2011.

Zizioulas, John D. Communion and Otherness. New York: T\&T Clark, 2006. 